\section{Racial and Ethnic Health Disparities among Fifth-Graders in Three Cities}

\author{
Mark A. Schuster, M.D., Ph.D., Marc N. Elliott, Ph.D., David E. Kanouse, Ph.D., \\ Jan L. Wallander, Ph.D., Susan R. Tortolero, Ph.D., Jessica A. Ratner, B.A., \\ David J. Klein, M.S., Paula M. Cuccaro, Ph.D., Susan L. Davies, Ph.D., \\ and Stephen W. Banspach, Ph.D.
}

ABSTRACT

\section{BACKGROUND}

For many health-related behaviors and outcomes, racial and ethnic disparities among adolescents are well documented, but less is known about health-related disparities during preadolescence.

\section{METHODS}

We studied 5119 randomly selected public-school fifth-graders and their parents in three metropolitan areas in the United States. We examined differences among black, Latino, and white children on 16 measures, including witnessing of violence, peer victimization, perpetration of aggression, seat-belt use, bike-helmet use, substance use, discrimination, terrorism worries, vigorous exercise, obesity, and self-rated health status and psychological and physical quality of life. We tested potential mediators of racial and ethnic disparities (i.e., sociodemographic characteristics and the child's school) using partially adjusted models.

\section{RESULTS}

There were significant differences between black children and white children for all 16 measures and between Latino children and white children for 12 of 16 measures, although adjusted analyses reduced many of these disparities. For example, in unadjusted analysis, the rate of witnessing a threat or injury with a gun was higher among blacks (20\%) and Latinos (11\%) than among whites $(5 \%)$, and the number of days per week on which the student performed vigorous exercise was lower among blacks (3.56 days) and Latinos (3.77 days) than among whites (4.33 days) ( $\mathrm{P}<0.001$ for all comparisons). After statistical adjustment, these differences were reduced by about half between blacks and whites and were eliminated between Latinos and whites. Household income, household highest education level, and the child's school were the most substantial mediators of racial and ethnic disparities.

\section{CONCLUSIONS}

We found that harmful health behaviors, experiences, and outcomes were more common among black children and Latino children than among white children. Adjustment for socioeconomic status and the child's school substantially reduced most of these differences. Interventions that address potentially detrimental consequences of low socioeconomic status and adverse school environments may help reduce racial and ethnic differences in child health. (Funded by the Centers for Disease Control and Prevention.)
From the Division of General Pediatrics, Department of Medicine, Boston Children's Hospital (M.A.S., J.A.R., D.J.K.), and the Department of Pediatrics, Harvard Medical School (M.A.S.) - both in Boston; RAND, Santa Monica (M.A.S., M.N.E., D.E.K.), and Psychological Sciences, Center of Excellence on Health Disparities, and Health Sciences Research Institute, University of California, Merced, Merced (J.L.W.) - both in California; the Center for Health Promotion and Prevention Research, University of Texas Health Science Center, Houston (S.R.T., P.M.C.); the Department of Health Behavior, School of Public Health, University of Alabama at Birmingham, Birmingham (S.L.D.); and the National Center for Chronic Disease Prevention and Health Promotion, Division of Adolescent and School Health, Centers for Disease Control and Prevention, Atlanta (S.W.B.). Address reprint requests to Dr. Schuster at the Division of General Pediatrics, Boston Children's Hospital, 300 Longwood Ave., Boston, MA 02115, or at mark.schuster@childrens.harvard.edu.

N Engl J Med 2012;367:735-45. DOI: 10.1056/NEJMsal114353 Copyright @ 2012 Massachusetts Medical Society. 
UBSTANTIAL RACIAL AND ETHNIC DISPARities have been documented among adolescents across a range of health-related behaviors, experiences, and outcomes, including the use of bike helmets ${ }^{1}$; witnessing of violence, experience of victimization, and perpetration of violence $^{1-6}$; experience of discrimination ${ }^{7}$; perceived health status ${ }^{8,9}$; and obesity. ${ }^{1-3,8,10,11}$ In contrast, we know much less about similar health-related issues among preadolescents. Several studies in this age group, which generally have involved small numbers of participants, examined one or two health behaviors, or included only two racial and ethnic groups, suggest that disparities among these children may mirror those that have been found among adolescents. 3,6,8-10,12,13

We conducted a study of racial and ethnic disparities in a broad range of health-related measures among fifth-grade children. These issues matter because of childhood morbidity and mortality and because health-related problems during childhood may have lifelong implications, either by establishing patterns that can persist into adulthood (e.g., cigarette use ${ }^{14,15}$ ) or by exerting long-term biologic influence (e.g., obesity ${ }^{16,17}$ ). Moreover, although racial and ethnic disparities have been identified at early ages (e.g., in rates of preterm birth and low birth weight, ${ }^{18-20}$ school readiness, ${ }^{18,21}$ and obesity ${ }^{22}$ ), our study assessed whether disparities that are typically associated with adolescence (e.g., violence, peer victimization, and substance use) emerge during adolescence or are already present during preadolescence. Understanding the mediators of such disparities may identify the most promising policy levers for reducing them.

\section{METHODS}

\section{STUDY PARTICIPANTS}

We analyzed data from Healthy Passages, a study of fifth-graders and their parents, which was conducted from August 2004 through September $2006 .{ }^{23}$ The participants were fifth-graders at public schools in districts in and around Birmingham, Alabama; Houston; and Los Angeles County. We then randomly sampled schools with probabilities designed to provide a balanced sample of children who were non-Latino black, Latino (regardless of race), and non-Latino white ${ }^{23}$ and distributed letters in classrooms requesting permission to contact children's primary caregivers (henceforth called parents).
Among 11,532 students in the sampled schools, the parents of 6663 children permitted us to contact them; of these children, 5147 (77\%) participated in the study. Each parent-child dyad completed computer-assisted personal interviews and audio-computer-assisted self-interviews (for sensitive questions) in English or Spanish. All parents provided written informed consent, and children provided written assent. A parental interview was lacking for 28 dyads, which left a sample of 5119. We included all dyads in adjusted analyses but report results for racial and ethnic groups with samples large enough for sufficiently precise estimation: black, Latino, and white (4612 dyads). Unadjusted rates were calculated for these 4612 dyads only. Relevant institutional review boards reviewed the research protocol.

\section{HEALTH-RELATED AND OTHER MEASURES}

We evaluated 16 health-related measures - witnessing of physical assault without a weapon, witnessing of threat or injury with a gun, victimization by peers, perpetration of nonphysical aggression, perpetration of physical aggression, cigarette smoking, alcohol use, seat-belt use, bike-helmet use, experience of discrimination, worrying about terrorism, obesity, vigorous exercise, health status, psychological quality of life, and physical quality of life - which are described in detail in Table S1 in the Supplementary Appendix (available with the full text of this article at NEJM.org). Parents reported sociodemographic characteristics; children reported all other measures (except obesity, which was derived from the body-mass index, as measured by researchers). For the children's evaluations of their psychological and physical quality of life, we used the Pediatric Quality of Life Inventory Psychological Health Summary Score and Physical Health Summary Score (www.pedsql.org).

\section{STATISTICAL ANALYSIS}

To determine the extent to which blacks and Latinos differed statistically from whites, we used logistic and linear regressions, respectively, for dichotomous and continuous measures, with adjustment for sociodemographic characteristics (the child's age and sex, marital status of the responding parent, highest education level in household, and total household income) and the child's school and neighborhood. ${ }^{23}$ Results from this model were presented as predictive margins, ${ }^{24}$ in which the regression models predict means and proportions for each racial and ethnic group, holding 
the distribution of all other respondent covariates constant across groups. We calculated differences from whites in these covariate-adjusted means and proportions to measure disparities. A "missing" category was included for income ( $8 \%$ missing) and education (1\%); mean imputation was used for the marital status of the responding parent $(<1 \%)$. We used Stata software, version 11 , to account for design and nonresponse weights, clustering of children within schools, and site stratification. $^{23}$

We conducted an analysis to assess the relative importance of covariates in relation to disparities among racial and ethnic groups. To do so, we defined four factors (conceptual classes of covariates) that might mediate the relationship between racial and ethnic group and health-related measures: the child's demographic characteristics (age and sex), parental marital status, socioeconomic status (household income and highest household education level), and the child's school. We ran a series of four partially adjusted models that excluded one factor at a time.

We linked the residential addresses of participants to data from U.S. Census 2000 at the blockgroup level. To determine whether health-related measures were more correlated with the child's school or characteristics of the child's neighborhood, additional regression models predicted each measure from the aforementioned covariates plus seven neighborhood characteristics: proportion of households below the poverty level, proportion of adults 25 years of age or older with no more than a 12th-grade education, proportion of adults 25 years of age or older with at least a bachelor's degree, median household income, and the proportions of residents who were Latino, non-Latino black, and non-Latino other races.

\section{RESULTS}

\section{DISPARITIES IN HEALTH-RELATED MEASURES}

The racial and ethnic groups varied widely in sociodemographic characteristics (Table 1). There were significant differences in all 16 health-related measures between black children and white children and significant differences in 12 of 16 measures between Latino children and white children (with similar rates of victimization by peers, perpetration of physical aggression, and use of tobacco and alcohol between Latino children and white children) (Table 2). For example, in unadjusted analyses, the rate of witnessing a threat or injury with a gun was higher among blacks (20\%) and Latinos (11\%) than among whites $(5 \%)$, and the number of days in the previous week during which the student had performed vigorous exercise was lower among blacks (3.56 days) and Latinos (3.77 days) than among whites (4.33 days) ( $\mathrm{P}<0.001$ for all comparisons). Additional disparities, as compared with whites, included lifetime cigarette use (5\% higher for blacks), consistent seat-belt use (15\% lower for blacks and 11\% lower for Latinos), consistent bike-helmet use (36\% lower for blacks and 32\% lower for Latinos), and obesity (12\% higher for blacks and 15\% higher for Latinos) ( $\mathrm{P}<0.01$ for lifetime cigarette use and $\mathrm{P}<0.001$ for all other comparisons).

Disparities in continuous measures, as compared with whites, included peer victimization (0.20 SD higher for blacks, $\mathrm{P}<0.001)$, discrimination (0.31 SD higher for blacks and 0.14 SD higher for Latinos; $\mathrm{P}<0.001$ and $\mathrm{P}<0.01$, respectively), and psychological and physical quality of life $(0.28 \mathrm{SD}$ lower for psychological quality of life and 0.24 SD lower for physical quality of life for blacks and 0.34 SD lower for psychological quality of life and 0.42 SD lower for physical quality of life for Latinos, $\mathrm{P}<0.001$ for all comparisons).

\section{EFFECTS OF ADJUSTMENT ON DISPARITIES}

Table 3 provides unadjusted and adjusted differences in measures between black children and white children and between Latino children and white children, as well as the net change in these differences after adjustment. Overall, adjustment by the full set of covariates eliminated disparities between black children and white children for 6 of 16 health-related measures $(P>0.05)$. Among the 10 differences that remained significant, 5 were reduced by at least $50 \%$, and 5 were reduced by 35 to $48 \%$. Of 12 disparities between Latino children and white children, 7 were eliminated by full adjustment, 2 were reduced by at least $50 \%$, and 3 were reduced by 22 to $47 \%$. For 3 measures (experiencing peer victimization and perpetrating physical and nonphysical aggression), Latino children had significantly better scores than white children after adjustment, even though in unadjusted analyses, Latino children had significantly worse scores than white children for one of these measures (perpetrating nonphysical aggression). Differences between black children and white children in witnessing a threat or injury with a gun and in performing vigorous exer- 


\begin{tabular}{|c|c|c|c|c|}
\hline Characteristics & $\begin{array}{c}\text { No. of } \\
\text { Participants }\end{array}$ & $\begin{array}{l}\text { White Non-Latino } \\
\qquad(\mathrm{N}=1249)\end{array}$ & $\begin{array}{c}\text { Black Non-Latino } \\
(\mathrm{N}=1748) \\
\text { percent }\end{array}$ & $\begin{array}{c}\text { Latino } \\
(\mathrm{N}=1615)\end{array}$ \\
\hline All participants & 4612 & 24 & 32 & 44 \\
\hline Female sex of child & 2328 & 47 & 49 & 50 \\
\hline \multicolumn{5}{|l|}{ Child's age } \\
\hline$<10 \mathrm{yr}$ & 17 & $<1$ & $<1$ & $<1$ \\
\hline $10 \mathrm{yr}$ & 2017 & 38 & 40 & 45 \\
\hline $11 \mathrm{yr}$ & 2245 & 58 & 49 & 46 \\
\hline$>11 \mathrm{yr}$ & 333 & 4 & 11 & 9 \\
\hline Child born outside the United Statest & 394 & 3 & $1 \ddagger$ & $21 \rrbracket$ \\
\hline Responding parent female & 4276 & 91 & $95 \sqrt{\pi}$ & $93 \ddagger$ \\
\hline \multicolumn{5}{|l|}{ Highest educational level in household $\uparrow$} \\
\hline Eighth grade or some high school & 914 & 3 & 10 & 48 \\
\hline High-school diploma or GED & 976 & 9 & 31 & 25 \\
\hline Some college & 1209 & 17 & 37 & 19 \\
\hline Four-year college degree or more & 1459 & 71 & $23 \sqrt{\Omega}$ & $8 \sqrt{\pi}$ \\
\hline \multicolumn{5}{|l|}{ Annual household income' } \\
\hline$<\$ 25,000$ & 1706 & 8 & 54 & 55 \\
\hline$\$ 25,000-\$ 49,999$ & 1081 & 16 & 27 & 33 \\
\hline$\$ 50,000-\$ 99,999$ & 827 & 35 & 14 & 10 \\
\hline$\geq \$ 100,000$ & 663 & 40 & $4 \pi$ & $2 \sqrt{2}$ \\
\hline \multicolumn{5}{|l|}{ Marital status of responding parent' } \\
\hline Married & 2613 & 80 & 36 & 62 \\
\hline Living with a partner & 326 & 1 & 5 & 14 \\
\hline Widowed & 81 & 1 & 3 & 1 \\
\hline Divorced or separated & 867 & 15 & 26 & 14 \\
\hline Never married & 712 & 2 & $31 \sqrt{1}$ & $9 \sqrt{9}$ \\
\hline
\end{tabular}

* All the listed characteristics were reported by the responding parent (i.e., the participating adult who is the child's parent or other primary caregiver). The numbers of participants do not total 4612 in some categories because of missing data. An additional 507 children were listed as being members of a racial and ethnic group described as "other"; their data were included in adjusted analyses but not unadjusted analyses. The reference group for comparisons among racial and ethnic groups is non-Latino white children. $P$ values were calculated with the use of the Wald chi-square test from a logistic regression predicting each covariate with race or ethnic group. All covariates were treated as dichotomous or linearly coded with the exception of marital status, which was treated as an unordered categorical trait. GED denotes general equivalency diploma.

$\uparrow \mathrm{P}<0.001$ for the overall comparison among groups.

$+\mathrm{P}<0.05$ for the comparison of dichotomous or multilevel covariate with white children.

$\int \mathrm{P}<0.001$ for the comparison of dichotomous or multilevel covariate with white children.

I $\mathrm{P}<0.01$ for the overall comparison among groups.

cise remained significant after adjustment but status, and school) in the adjustment of dispariwere reduced by about half; disparities between ties. For example, the rate of witnessing a threat Latino children and white children in both of or injury with a gun was $15 \%$ higher among these measures were eliminated after adjustment. black children than among white children before

Figure 1 illustrates the relative importance of adjustment, but full adjustment reduced this the four factors (i.e., child's demographic charac- disparity to $8 \%$, a reduction of 7 percentage teristics, parental marital status, socioeconomic points (Table 3). 


\begin{tabular}{|c|c|c|c|}
\hline Measure $\grave{\dagger}$ & $\begin{array}{l}\text { White Non-Latino } \\
\qquad(\mathrm{N}=1249)\end{array}$ & $\begin{array}{l}\text { Black Non-Latino } \\
(\mathrm{N}=1748)\end{array}$ & $\begin{array}{l}\text { Latino } \\
(\mathrm{N}=1615)\end{array}$ \\
\hline \multicolumn{4}{|l|}{ Witnessed violence in past $12 \mathrm{mo}(\%)$} \\
\hline Saw physical assault without weapon "lots of times" & 4 & $19 \%$ & $7 \sqrt{\int}$ \\
\hline Saw threat or injury with a gun & 5 & $20 \%$ & $11 \ddagger$ \\
\hline Victimized by peers in past 12 mo (z score) & -0.08 & $0.12 \div$ & -0.02 \\
\hline \multicolumn{4}{|l|}{ Aggression in past 30 days (z score) } \\
\hline Perpetrated nonphysical aggression & -0.17 & $0.25 \div$ & $-0.07 \sqrt{\int}$ \\
\hline Perpetrated physical aggression & -0.14 & $0.24 \dagger$ & -0.08 \\
\hline \multicolumn{4}{|l|}{ Substance use (\%) } \\
\hline Smoked cigarette (ever) & 5 & 109 & 6 \\
\hline Drank alcohol (past $12 \mathrm{mo}$ ) & 5 & $7 \sqrt{\int}$ & 5 \\
\hline \multicolumn{4}{|l|}{ Injury prevention (\%) } \\
\hline Always wears seat belt & 76 & $61 \div$ & $66 \%$ \\
\hline Always wears bike helmet & 49 & $14 冖$ & $18 \div$ \\
\hline \multicolumn{4}{|l|}{ Social issues (z score) } \\
\hline Experienced discrimination & -0.17 & $0.14 \nmid$ & $-0.02 q$ \\
\hline Worried about terrorist attacks & -0.74 & $0.06 \div$ & $0.39 \%$ \\
\hline \multicolumn{4}{|l|}{ Exercise and obesity } \\
\hline Classified as obese (\%) & 17 & $29 \%$ & $32 \ddagger$ \\
\hline No. of days of performing vigorous exercise in past 7 days & 4.33 & $3.56 \div$ & $3.77 \%$ \\
\hline \multicolumn{4}{|l|}{ Health status and quality of life } \\
\hline Reported fair or poor health (\%) & 7 & $15 \%$ & $27 \dagger$ \\
\hline Psychological quality of life in past 30 days (z score) & 0.23 & $-0.06 \div$ & $-0.11 \div$ \\
\hline Physical quality of life in past 30 days (z score) & 0.26 & $0.02 \div$ & $-0.16 \div$ \\
\hline
\end{tabular}

* All measures except for obesity were reported by the child. Complete data were available except for bike-helmet use (number of children who have ridden a bicycle: whites, 1106; blacks, 1481; and Latinos, 1306) and obesity (reliable height and weight available for 1192 whites, 1627 blacks, and 1476 Latinos). The reference group for comparisons among racial and ethnic groups is non-Latino white. $P$ values were calculated with the use of a logistic or linear regression predicting each outcome with racial or ethnic group.

$\dagger$ Responses are reported as either percentages of participants (for dichotomous measures) or z scores with a mean of 0 and a standard deviation of 1 (for continuous measures). (Details about scoring and instruments of measurement are provided in Table SI in the Supplementary Appendix.) Higher values indicate a greater level of response to each measure.

$\div \mathrm{P}<0.001$

$\int P<0.05$.

ๆf $P<0.01$.

The biggest independent contributors to reductions in disparities with adjustment were the child's school and socioeconomic status (i.e., household income and highest education), with the child's demographic characteristics and parental marital status having much smaller independent associations with racial and ethnic differences. The relative importance of each factor varied according to racial and ethnic group and the health-related measure. The child's school was the most important mediator of disparities between black children and white children for 11 of 16 measures, whereas socioeconomic status was the largest mediator of disparities between Latino children and white children for 10 measures. For measures of witnessing a gun threat or injury and performing vigorous exercise, changes in disparities because of adjustment were driven almost entirely by the child's school and socioeconomic status, with school contributing more 


\begin{tabular}{|c|c|c|c|c|c|c|}
\hline \multirow[t]{2}{*}{ Measure' } & \multicolumn{3}{|c|}{$\begin{array}{l}\text { Black Non-Latino } \\
\text { (Difference from Whites) }\end{array}$} & \multicolumn{3}{|c|}{$\begin{array}{l}\text { Latino } \\
\text { (Difference from Whites) }\end{array}$} \\
\hline & Unadjusted & Adjusted & Difference $\mathbb{}$ & Unadjusted & Adjusted $\leftarrow$ & Difference $\mathbb{}$ \\
\hline \multicolumn{7}{|l|}{ Witnessed violence in past 12 mo (\%) } \\
\hline Saw physical assault without weapon "lots of times" & 149 & $5 \|$ & -9 & $3 \|$ & -2 & -5 \\
\hline Saw threat or injury with a gun & 159 & 89 & -7 & 69 & -1 & -7 \\
\hline Victimized by peers in past 12 mo (z score) & 0.209 & -0.07 & -0.28 & 0.06 & $-0.18 * *$ & -0.24 \\
\hline \multicolumn{7}{|l|}{ Aggression in past 30 days (z score) } \\
\hline Perpetrated nonphysical aggression & 0.429 & $0.19 \|$ & -0.23 & $0.10 \|$ & $-0.22 * *$ & -0.32 \\
\hline Perpetrated physical aggression & 0.389 & $0.23 * *$ & -0.15 & 0.05 & $-0.15 \|$ & -0.20 \\
\hline \multicolumn{7}{|l|}{ Substance use (\%) } \\
\hline Smoked cigarette (ever) & $5 * *$ & 1 & -4 & 1 & -3 & -4 \\
\hline Drank alcohol (past $12 \mathrm{mo}$ ) & $2 \|$ & 0 & -2 & 1 & -1 & -2 \\
\hline \multicolumn{7}{|l|}{ Injury prevention (\%) } \\
\hline Always wears seat belt & -159 & $-7 \|$ & 8 & -119 & $-8 \|$ & 2 \\
\hline Always wears bike helmet & -369 & -219 & 15 & -329 & -179 & 15 \\
\hline \multicolumn{7}{|l|}{ Social issues (z score) } \\
\hline Experienced discrimination & 0.319 & $0.20 * *$ & -0.11 & $0.14 * *$ & -0.10 & -0.24 \\
\hline Worried about terrorist attacks & 0.799 & 0.369 & -0.43 & 1.129 & 0.509 & -0.62 \\
\hline \multicolumn{7}{|l|}{ Exercise and obesity } \\
\hline Classified as obese (\%) & 129 & $8 * *$ & -4 & 159 & 129 & -4 \\
\hline $\begin{array}{l}\text { No. of days of performing vigorous exercise in past } \\
7 \text { days }\end{array}$ & -0.779 & $-0.37 \|$ & 0.40 & -0.569 & -0.15 & 0.41 \\
\hline \multicolumn{7}{|l|}{ Health status and quality of life } \\
\hline Reported fair or poor health (\%) & 79 & 3 & -4 & 209 & $9 * *$ & -11 \\
\hline Psychological quality of life in past 30 days (z score) & -0.289 & 0.02 & 0.30 & -0.349 & 0.08 & 0.42 \\
\hline Physical quality of life in past 30 days (z score) & -0.249 & 0.01 & 0.25 & -0.429 & -0.03 & 0.39 \\
\hline
\end{tabular}

* All measures except obesity were reported by the child. Adjusted means and proportions are provided in Table S2 in the Supplementary Appendix.

$\dagger$ Responses are reported as either percentages of participants (for dichotomous measures) or z scores with a mean of 0 and a standard deviation of 1 (for continuous measures). Higher values indicate a greater level of response to each measure.

$¥$ Adjusted models include indicators of racial and ethnic group and additionally control for highest education in household (categorical), household income (categorical), parental marital status (married or living with a partner vs. other), age and sex of child, and child's school. Models include data from 507 children who were classified as "other" race or ethnic group; results for these children are not shown. Differences from whites in covariate-adjusted means and proportions were calculated to determine disparities. Adjusted means for each racial and ethnic group were calculated by fitting a model on observed data, setting the indicators for racial and ethnic group for all 5119 children in the sample to that racial and ethnic group, generating predicted values, and averaging the predicted values. The differences of these means between the children in each group and white children are the adjusted differences listed here.

$\int$ Differences between unadjusted and adjusted values are measured in percentage points (for dichotomous measures) and in standard deviations (for continuous measures). Differences were rounded at the last stage of calculation.

q $P<0.001$.

$\| \quad P<0.05$.

$* * \mathrm{P}<0.01$.

for disparities between black children and white children and socioeconomic status contributing more for disparities between Latino children and white children.

A sensitivity test showed that Census-linked neighborhood characteristics were significantly associated with 10 of 16 measures when school was omitted from the analyses, although there was little evidence that neighborhood characteristics were significantly associated with measures inde- 
pendently of school ( $\mathrm{P}<0.05$ for 1 of 16 measures). However, school remained a significant predictor for all 16 measures $(\mathrm{P}<0.001)$, even when neighborhood characteristics were included in the analysis.

\section{DISCUSSION}

Our study of fifth-graders attending public schools in the greater Birmingham, Houston, and Los Angeles areas showed striking disparities across racial and ethnic groups for a broad range of health-related behaviors, experiences, and outcomes, including obesity, vigorous exercise, witnessing of violence, seat-belt use, and self-reported health status and psychological and physical quality of life. Black children and Latino children fared worse than white children in almost every category. For nearly all health-related measures that we examined, adjustment for available sociodemographic characteristics and the child's school eliminated a sizable portion of these disparities and, in some cases, fully accounted for the disparities. In general, adjustment for these factors affected disparities between Latino children and white children more substantially than disparities between black children and white children. Fewer disparities between Latino children and white children persisted after adjustment, and significant differences emerged in a favorable direction for Latino children for several variables (experiencing peer victimization and perpetrating physical and nonphysical aggression). Although our study incorporated a wide variety of covariates, unavailable indicators of socioeconomic status, such as wealth and occupation, might have further narrowed adjusted disparities.

Previous research has documented that the prevalence of many health-related problems increases as children grow and that substantial racial and ethnic disparities exist by adolescence. , $2,4,6,25^{2}$ Although some studies have included younger children (e.g., $\leq 18$ years of age) $6,8,9,26,27$ and a few have focused exclusively on younger age groups, ${ }^{12,13,28-30}$ there is limited information on whether disparities in health-related problems that are often associated with adolescence appear earlier than adolescence. In our study, the prevalence rates of many problems were high and significant disparities already existed among preadolescents. The overall pattern of disparities in our preadolescent sample closely resembled that for older age groups, with black children having the greatest number of disparities, followed by Latino children. ${ }^{2}$

Previous research among adults has identified socioeconomic status and neighborhood characteristics as important mediators of racial and ethnic health disparities. ${ }^{31-34}$ We found that similar factors may influence preadolescent disparities. In particular, both the child's school and socioeconomic status independently mediated disparities. Whereas a child's school may reflect the neighborhood as well as school environment, since many children attend a school near their home, sensitivity analyses showed that school had an additional unique effect beyond neighborhood characteristics but not vice versa. In contrast, parental marital status appeared to have little independent association with racial and ethnic disparities in health-related problems. These patterns held for each racial and ethnic group for most of the health-related measures. Indicators of socioeconomic status more often mediated disparities between Latino children and white children, whereas the school or neighborhood environment was more often linked to disparities between black children and white children. These findings are consistent with studies among adults, which suggest both that socioeconomic status is an important mediator of racial and ethnic disparities and that, particularly for blacks, disparities are present even within income or education levels. ${ }^{34-36}$ Further research is necessary to explore factors influencing racial and ethnic disparities that are not fully captured by the sociodemographic and contextual measures used in our study. Such contributors might include additional factors involving socioeconomic status and neighborhood characteristics, discrimination, maturation level, and parenting (e.g., differences in bike-helmet use might reflect differences in parental monitoring).

Many of the health behaviors and experiences that we measured are major contributors to youth morbidity and mortality. For example, unintentional injuries are the leading cause of death among both children and adolescents. ${ }^{37}$ In each racial and ethnic group, many children in our sample did not always wear a seat belt, and most did not always wear a bike helmet. Black children and Latino children were substantially less likely than white children to wear a seat belt or bike helmet.

Violence is the second largest cause of death 


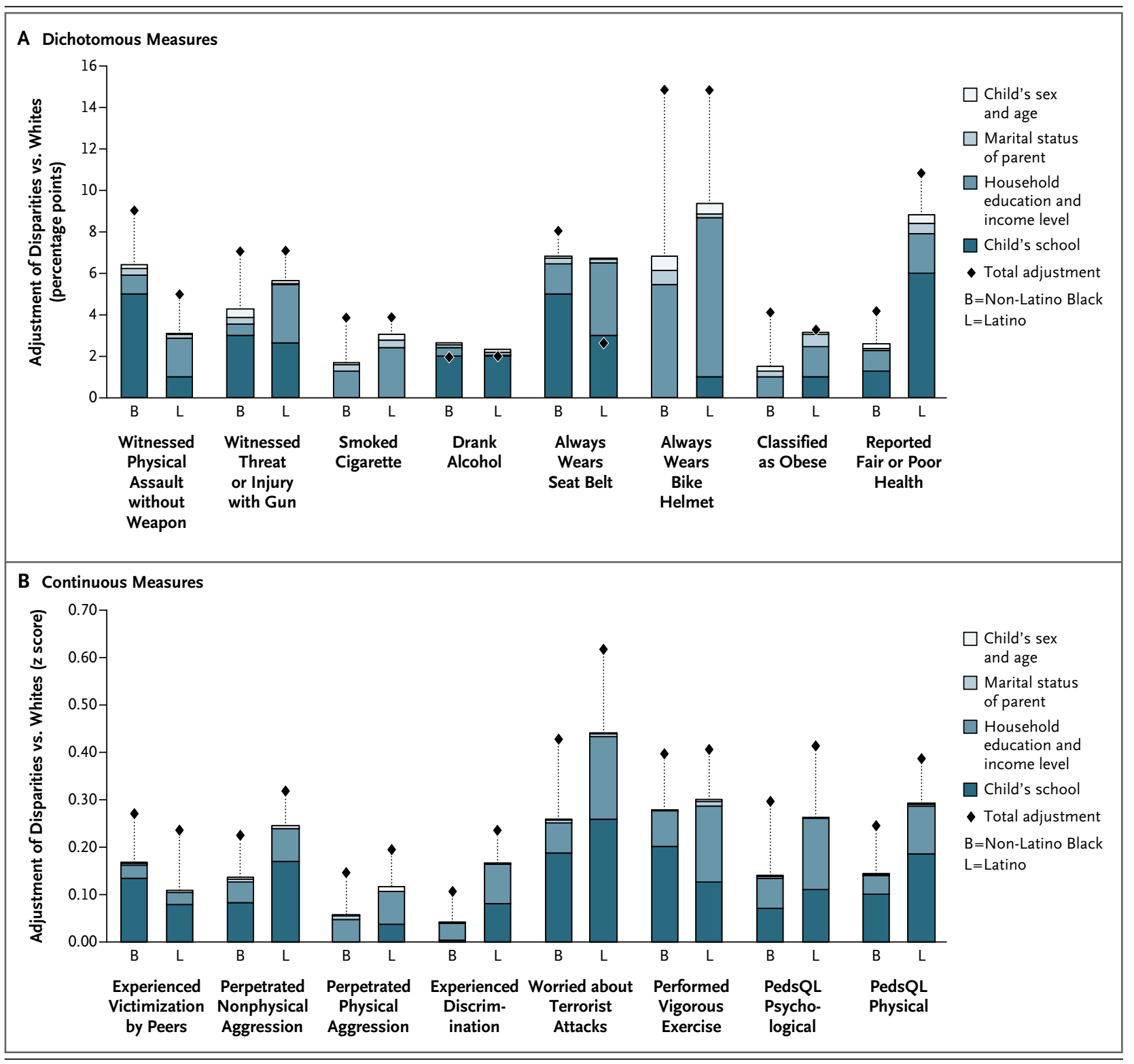

among adolescents and the leading cause of death for black male adolescents. ${ }^{37}$ Peer victimization and exposure to community violence are linked to dysregulated physiologic stress responses ${ }^{38-41}$ and are associated with substantial mental and physical health problems among youth. ${ }^{42,43}$ Among black children in our sample, exposure to violence was already prevalent, with 1 in 5 children witnessing physical assault without a weapon many times and 1 in 5 witnessing a threat or injury with a gun in the past year. Disparities between black children and white children were seen in measures of witnessing violence, being victimized by peers, and perpetrating aggression. For most of these measures, about half of the disparity between black children and white children remained after adjustment. This suggests that there might be unmeasured factors putting black preadolescents at greater risk for these experiences and behaviors. In contrast, there might be unmeasured protective factors for these measures among Latinos. Although Latino children witnessed violence, were victimized by peers, and perpetrated aggression at levels similar to or greater than the levels among white children, after adjustment for sociodemographic 
Figure 1 (facing page). Total Adjustment of Disparities between Black Fifth-Graders and Latino Fifth-Graders, as Compared with White Fifth-Graders, for 16 Measures of Health-Related Behaviors, Experiences, and Outcomes.

Shown are the differences between the disparities in responses among black fifth-graders and Latino fifthgraders, as compared with their white counterparts, and the values after adjustment for four factors: the child's sex and age, parental marital status, household education and income level, and the child's school. The differences are shown in percentage points for dichotomous measures (Panel $A$ ) and in $z$ scores with a mean of 0 and a standard deviation of 1 for continuous measures (Panel B). The diamonds represent the total net adjustment for all four covariates, which, in general, is the sum of the single-factor adjustments and any adjustments from the combined effects of the multiple covariates. For example, the rate of witnessing a threat or injury with a gun was $15 \%$ higher among black children than among white children before adjustment, but full adjustment reduced this disparity to $8 \%$, a reduction of 7 percentage points, as shown. The diamond above the column for this measure reflects a reduction of 7 percentage points owing to adjustment for all covariates in combination. The stacked segments show how much of this reduction can be uniquely attributed to each of the four covariates. About 3 of those 7 percentage points can be attributed uniquely to adjustment for the child's school, and less than 1 percentage point can be attributed uniquely to each of the other three covariates. The remaining 3 percentage points, represented by the vertical dashed line connecting the top of the column to the diamond above it, can be attributed jointly to a combination of the four covariates. The diamond symbol usually appears above the top of the column because of the adjustment jointly explained by multiple covariates. In three cases, however, the diamond is shown below the top of the column because one or more of the covariates reduced the overall adjustment, as represented by segments with zero height rather than negative height. Vigorous exercise is reported as the number of days in the past 7 days rather than as a $z$ score. PedsQL denotes Pediatric Quality of Life Inventory.

characteristics and school, they had lower rates for several measures. Other studies have shown that black adolescents and young adults witness, perpetrate, and are victims of violence more commonly than whites; patterns among Latinos have been less consistent but are largely similar to those among blacks. ${ }^{1-6,44}$ Our finding that more black children and Latino children experienced discrimination is consistent with the results of studies involving older groups, ${ }^{7}$ and our finding that blacks and particularly Latinos worried more about terrorism corresponds with previous findings for both children ${ }^{45}$ and adults..$^{46,47}$
The prevalence of obesity was high among the children in our study, ranging from 1 in 6 among whites to 1 in 3 among blacks and Latinos. Although these rates are somewhat higher than those found in previous research, the extent of the disparity is similar. ${ }^{10,48}$ Of note, in our study, disparities in obesity were less well explained by sociodemographic or contextual factors than were other problems.

Our data have implications for efforts to improve child health at both individual and community levels. First, our findings suggest that clinicians should recognize that some consequential health-related behaviors and experiences that are associated with adolescence have already begun in elementary school. Even when they have not, counseling and screening can reasonably begin in anticipation of what may soon emerge. Longitudinal research is needed to show whether disparities worsen or subside and what their consequences are.

Although the picture is complex and varies according to measure, our findings identified major correlates of disparities among preadolescents and thus potential pathways for reducing them. Disparities that are closely associated with socioeconomic status (e.g., bike-helmet use and cigarette smoking) might be ameliorated through educational interventions targeted at parental health literacy or subsidization of safety equipment. This type of approach might be particularly helpful for improving disparities between Latino children and white children. Disparities that are tied to school (e.g., peer victimization and perpetration of nonphysical aggression) might be improved through efforts to change the school environment, such as school-based antibullying programs. Our finding that a child's school matters above and beyond his or her neighborhood suggests that school-based approaches might merit particular consideration. Such contextual approaches might be especially important for improving the health of black children. To make long-lasting improvements in disparities related to school and socioeconomic status, broader efforts in areas that affect health, such as education, employment, and housing, might be beneficial. ${ }^{31,33,34,36,49}$ Finally, given that substantial disparities sometimes remain after adjustment (e.g., for obesity), additional research is needed to identify remaining factors that might be associated with these disparities.

Our study has several limitations. First, the data 
were obtained in only three metropolitan areas, so results might differ elsewhere, especially where differences in socioeconomic status are smaller among racial and ethnic groups. Second, all measures besides children's body-mass index were gathered through self-report by children and their parents. Finally, it is possible that schoolrelated findings capture unmeasured aspects of the neighborhood beyond characteristics that were tested in our analysis.

In summary, our findings revealed marked racial and ethnic disparities among fifth-graders across a range of health-related experiences, behaviors, and outcomes, many of which were strongly associated with the child's school and the socioeconomic status of the family. The fact that disparities are prevalent among preadolescents and, in many cases, mirror disparities found in older age groups suggests that intervention efforts may need to begin early.

Supported by cooperative agreements (CCU409679, CCU609653, CCU915773, U48DP000046, U48DP000057, U48DP000056, U19DP002663, U19DP002664, and U19DP002665) with the Centers for Disease Control and Prevention.

Disclosure forms provided by the authors are available with the full text of this article at NEJM.org.

We thank Jeremy Y. Feng and Katherine D. Vestal for research assistance, other Healthy Passages staff, and the study participants.
REFERENCES

1. High school youth risk behavior survey data. Atlanta: Centers for Disease Control and Prevention, 2009 (http://apps .nccd.cdc.gov/youthonline).

2. Harris KM, Gordon-Larsen P, Chantala K, Udry JR. Longitudinal trends in race/ethnic disparities in leading health indicators from adolescence to young adulthood. Arch Pediatr Adolesc Med 2006;160:74-81.

3. Oberg CN, Rinaldi M. Pediatric health disparities. Curr Probl Pediatr Adolesc Health Care 2006;36:251-68.

4. Mulye TP, Park MJ, Nelson CD, Adams $\mathrm{SH}$, Irwin CE Jr, Brindis CD. Trends in adolescent and young adult health in the United States. J Adolesc Health 2009;45:824.

5. Crouch JL, Hanson RF, Saunders BE, Kilpatrick DG, Resnick HS. Income, race/ ethnicity, and exposure to violence in youth: results from the national survey of adolescents. J Commun Psychol 2000;28: 625-41.

6. Bernard SJ, Paulozzi LJ, Wallace DL. Fatal injuries among children by race and ethnicity - United States, 1999-2002. MMWR Surveill Summ 2007;56(SS-5):116.

7. Sanders-Phillips K, Settles-Reaves B, Walker D, Brownlow J. Social inequality and racial discrimination: risk factors for health disparities in children of color. Pediatrics 2009;124:Suppl 3:S176-S186.

8. Flores G. Technical report - racial and ethnic disparities in the health and health care of children. Pediatrics 2010; 125(4):e979-e1020.

9. Wen M. Racial and ethnic differences in general health status and limiting health conditions among American children: parental reports in the 1999 national survey of America's families. Ethn Health 2007;12:401-22.

10. Hedley AA, Ogden CL, Johnson CL, Carroll MD, Curtin LR, Flegal KM. Prevalence of overweight and obesity among US children, adolescents, and adults, 19992002. JAMA 2004;291:2847-50.
11. Gordon-Larsen P, Adair LS, Popkin BM. The relationship of ethnicity, socioeconomic factors, and overweight in US adolescents. Obes Res 2003;11:121-9. [Erratum, Obes Res 2003;11:597.]

12. Campaigne BN, Morrison JA, Schumann BC, et al. Indexes of obesity and comparisons with previous national survey data in 9- and 10-year-old black and white girls: the National Heart, Lung, and Blood Institute Growth and Health Study. J Pediatr 1994;124:675-80.

13. Simons-Morton BG, Haynie DL. Psychosocial predictors of increased smoking stage among sixth graders. Am J Health Behav 2003;27:592-602.

14. Riggs NR, Chou CP, Li C, Pentz MA. Adolescent to emerging adulthood smoking trajectories: when do smoking trajectories diverge, and do they predict early adulthood nicotine dependence? Nicotine Tob Res 2007;9:1147-54.

15. Brook DW, Brook JS, Zhang C, Whiteman M, Cohen P, Finch SJ. Developmental trajectories of cigarette smoking from adolescence to the early thirties: personality and behavioral risk factors. Nicotine Tob Res 2008;10:1283-91.

16. Dietz WH. Health consequences of obesity in youth: childhood predictors of adult disease. Pediatrics 1998;101:518-25. 17. Biro FM, Wien M. Childhood obesity and adult morbidities. Am J Clin Nutr 2010;91:1499S-1505S.

18. Lynch JL. Infant health, race/ethnicity, and early educational outcomes using the ECLS-B. Sociol Inq 2011;81:499-526.

19. David RJ, Collins JW Jr. Differing birth weight among infants of U.S.-born blacks, African-born blacks, and U.S.-born whites. N Engl J Med 1997;337:1209-14.

20. Lu MC, Halfon N. Racial and ethnic disparities in birth outcomes: a lifecourse perspective. Matern Child Health J 2003;7:13-30.

21. Fiscella K, Kitzman H. Disparities in academic achievement and health: the intersection of child education and health policy. Pediatrics 2009;123:1073-80.
22. Anderson SE, Whitaker RC. Prevalence of obesity among US preschool children in different racial and ethnic groups. Arch Pediatr Adolesc Med 2009;163:344-8.

23. Windle $M$, Grunbaum JA, Elliott $M$, et al. Healthy passages: a multilevel, multimethod longitudinal study of adolescent health. Am J Prev Med 2004;27:164-72.

24. Graubard BI, Korn EL. Predictive margins with survey data. Biometrics 1999; 55:652-9.

25. Singh GK, Kogan MD, Siahpush M, van Dyck PC. Independent and joint effects of socioeconomic, behavioral, and neighborhood characteristics on physical inactivity and activity levels among US children and adolescents. J Community Health 2008;33:206-16.

26. Chen E, Martin AD, Matthews KA. Understanding health disparities: the role of race and socioeconomic status in children's health. Am J Public Health 2006; 96:702-8.

27. Flores G, Tomany-Korman SC. Racial and ethnic disparities in medical and dental health, access to care, and use of services in US children. Pediatrics 2008; 121(2):e286-e298. [Erratum, Pediatrics 2009;124:999-1000.]

28. Harrell JS, Bangdiwala SI, Deng S, Webb JP, Bradley C. Smoking initiation in youth: the roles of gender, race, socioeconomics, and developmental status. J Adolesc Health 1998;23:271-9.

29. McDermott RJ, Clark-Alexander BJ, Westhoff WW, Eaton DK. Alcohol attitudes and beliefs related to actual alcohol experience in a fifth-grade cohort. J Sch Health 1999;69:356-61.

30. Vega WA, Zimmerman RS, Warheit GJ, Apospori E, Gil AG. Risk factors for early adolescent drug use in four ethnic and racial groups. Am J Public Health 1993;83:185-9.

31. Adler NE, Rehkopf DH. U.S. disparities in health: descriptions, causes, and mechanisms. Annu Rev Public Health 2008;29:235-52.

32. Williams DR, Jackson PB. Social 
sources of racial disparities in health Health Aff (Millwood) 2005;24:325-34.

33. Laveist T, Pollack K, Thorpe R Jr, Fesahazion R, Gaskin D. Place, not race: disparities dissipate in southwest Baltimore when blacks and whites live under similar conditions. Health Aff (Millwood) 2011; 30:1880-7.

34. Williams DR, Sternthal M. Understanding racial-ethnic disparities in health: sociological contributions. J Health Soc Behav 2010;51:Suppl:S15-S27.

35. Braveman PA, Cubbin C, Egerter S, Williams DR, Pamuk E. Socioeconomic disparities in health in the United States: what the patterns tell us. Am J Public Health 2010;100:Suppl 1:S186-S196.

36. Braveman PA, Egerter SA, Mockenhaupt RE. Broadening the focus: the need to address the social determinants of health. Am J Prev Med 2011;40:S4-18.

37. Heron HP, Hoyert DL, Xu J, Scott C, Tejada-Vera B. Death: preliminary data for 2006. Hyattsville, MD: National Center for Health Statistics, 2008.

38. Suglia SF, Staudenmayer J, Cohen S, Wright RJ. Posttraumatic stress symptoms related to community violence and children's diurnal cortisol response in an urban community-dwelling sample. Int J Behav Med 2010;17:43-50.

39. Vaillancourt T, Duku E, Becker S, et al. Peer victimization, depressive symptoms, and high salivary cortisol predict poorer memory in children. Brain Cogn 2011;77:191-9.

40. Knack JM, Jensen-Campbell LA, Baum A. Worse than sticks and stones? Bullying is associated with altered HPA axis functioning and poorer health. Brain Cogn 2011;77:183-90.

41. Cooley-Quille M, Boyd RC, Frantz E, Walsh J. Emotional and behavioral impact of exposure to community violence in inner-city adolescents. J Clin Child Psychol 2001;30:199-206.

42. Reijntjes A, Kamphuis JH, Prinzie P, Telch MJ. Peer victimization and internalizing problems in children: a meta-analysis of longitudinal studies. Child Abuse Negl 2010;34:244-52.

43. Rigby K. Consequences of bullying in schools. Can J Psychiatry 2003;48:583-90. 44. Sampson RJ, Morenoff JD, Raudenbush S. Social anatomy of racial and ethnic disparities in violence. Am J Public
Health 2005;95:224-32. [Erratum, Am J Public Health 2006;96:591.]

45. Stein BD, Jaycox LH, Elliott MN, et al. The emotional and behavioral impact of terrorism on children: results from a national survey. Appl Dev Sci 2004;8:18494.

46. Eisenman DP, Glik D, Ong $M$, et al. Terrorism-related fear and avoidance behavior in a multiethnic urban population. Am J Public Health 2009;99:168-74.

47. Stein BD, Elliott MN, Jaycox LH, et al. A national longitudinal study of the psychological consequences of the September 11, 2001 terrorist attacks: reactions, impairment, and help-seeking. Psychiatry 2004;67:105-17.

48. Singh GK, Siahpush M, Kogan MD. Rising social inequalities in US childhood obesity, 2003-2007. Ann Epidemiol 2010; 20:40-52. [Erratum, Ann Epidemiol 2010; 20:250.]

49. Woolf $\mathrm{SH}$, Braveman P. Where health disparities begin: the role of social and economic determinants - and why current policies may make matters worse. Health Aff (Millwood) 2011;30:1852-9.

Copyright (๑) 2012 Massachusetts Medical Society. 